\title{
The Antibacterial and Antioxidant Effect of Salvadora persica on Antibiotic Resistant Strains
}

\author{
Z. Mammad, S. Hsaine, T. Djassinra, K. Ounine \\ Department of Biology, Health and Environment, Applied Microbiology Team, Faculty of Sciences, Ibn Tofail University, Kenitra, \\ Morocco \\ Email: Zeinab.yaya@gmail.com
}

How to cite this paper: Mammad, Z., Hsaine, S., Djassinra, T. and Ounine, K. (2018) The Antibacterial and Antioxidant Effect of Salvadora persica on Antibiotic Resistant Strains. American Journal of Plant Sciences, 9, 1478-1485.

https://doi.org/10.4236/ajps.2018.97108

Received: May 15, 2018

Accepted: June 22, 2018

Published: June 25, 2018

Copyright $\odot 2018$ by authors and Scientific Research Publishing Inc. This work is licensed under the Creative Commons Attribution International License (CC BY 4.0).

http://creativecommons.org/licenses/by/4.0/

\begin{abstract}
Many efforts have been devoted to studying the inhibitory effect of Salvadora persica (Miswak) on oral microorganisms. However, information regarding its antibacterial activity against other human pathogens is rare. Particularly, against Pseudomonas aeruginosa, Acinetobacter baumannii and Enterobacter cloacae. The purpose of this piece of work was to evaluate the antioxidant power and in vitro antibacterial activities of Salvadora persica extract against the three bacterial clinical isolates mentioned above. Therefore, the action of Salvadora persica extract on the three germs, studied via the aromatograms method, has given an inhibition zone 20,18 and 14 respectively on Pseudomonas aeruginosa, Acinetobacter baumannii and Enterobacter cloacae. The methanol extract of Salvadora persica using Soxhlet has given an output of 19\%. The antioxidant evaluation, which was performed using the DPPH (1,1-diphenyl-2-picryl-hydrazyl), free radical scavenging method, indicated that the methanol extract showed good antioxidant efficiency (IC50 $=15.47$ $\mathrm{mg} / \mathrm{ml}$ ) compared to ascorbic acid with (IC50 $=0.097 \mathrm{mg} / \mathrm{ml}$ ).
\end{abstract}

\section{Keywords}

Salvadora persica, Pseudomonas aeruginosa, Acinetobacter baumannii and Enterobacter cloacae, Extract, Soxhlet, DPPH, Antioxidant, Ascorbic Acid

\section{Introduction}

A medicinal plant is any plant containing one or more active ingredients capable of preventing, relieving or curing diseases [1]. Beside the antibiotics most known, different aromatic plants are characterized by the synthesis of odorous 
molecules which constitute the so-called essential oils or essences known, for a long time, for their antiseptic activities [2] and their therapeutic activities in traditional medicine [3]. It has shown that essential oils increase the level of oxygen and activate the immune system in animal cells [4]. In addition, they inhibit an effect on murine cancer cells in culture.

The chemical composition of essential oils is quite complex [5], terpene and aromatic compounds represent the main constituents; including low concentrations of organic acids, ketones and volatile coumarins. The nature of the main compound (phenol, alcohol, aldehyde, ketone...) plays a major role in the effectiveness of their biological effects [6], as well as the minority compounds. The use of plant extracts for antimicrobial activity has shown that these plants represent a potential source of new anti-infection agents. Therefore, it considered useful to contribute to the study of this activity.

Salvadora persica, also called Miswak, reported to have powerful effect for dental complaints. The roots of this tree have been used for cleaning teeth since antiquity. Moreover, they are the most used medicinal plants for oral hygiene among the Muslim community [7]. The tree used by many Islamic communities as toothbrushes. Thus, it has been scientifically proved to be very helpful in preventing tooth decay [8], even when used alone and without other methods of cleaning teeth. A variety of chemical components has been identified in extracts of Salvadora persica, some of these biologically active chemical constituents such as Sterol, Phenol, Palmitic Acid, Carvacrol, Eugenol, and Oleic Acids [9]. The purpose of our research is to demonstrate the antibacterial power against drug-resistant bacteria and to know the antioxidant effect of Salvadora persica.

\section{Materials and Methods}

\subsection{Extraction Methods}

Stems of Salvadora persica samples, imported from Saoudi Arabia, crushed with mortar and extracted by Soxhlet, with $80 \mathrm{~g}$ of Miswak powder and $750 \mathrm{ml}$ of methanol, at a temperature of $60^{\circ} \mathrm{C}$ for 12 hours until the solvent is colorless then, the extract obtained is concentrated in a rotary evaporator. Later, it kept at $4^{\circ} \mathrm{C}$ in the dark.

\subsection{Bacterial Strains}

Salvadora persica extract tested in the microbiology laboratory ISPITS flap on three strains of bacteria: Pseudomonas aeruginosa, Acinetobacter baumanni and Enterobacter cloacae. These bacterial strains obtained from Mohammed V Military Hospital Instruction Laboratory in Rabat (city situated in North West of Morocco).

\subsection{Preparation of the Inoculum}

Species were pre-seeded, individually, in BHIB broth at $37^{\circ} \mathrm{C}$ for $18 \mathrm{~h}$ to $24 \mathrm{~h}$. 
Then, 4 to 5 isolated bacterial colonies suspended in physiological water at $0.9 \%$ $\mathrm{NaCl}$. Adjusted to the Mc Farland 0.5 standard $\left(1.5 \times 10^{8} \mathrm{CFU} / \mathrm{ml}\right)$ using a spectrophotometer, corresponding to an optical density OD, between 0.08 and 0.1 at $625 \mathrm{~nm}$, corresponding to a suspension containing about $10^{8} \mathrm{CFU} / \mathrm{ml}$.

\subsection{Disk Diffusion Method}

\section{1) Antibiogram and aromatogram}

Antibiogram involves flooding an agar plate with a bacterial strain of nutritive broth of a known title. Then, organized the sterile discs on the agar plate. These discs formed by sterilized filter paper $6 \mathrm{~mm}$ in diameter, possibly using antibiotic discs as references to specify the effect of the extract in the test.

On the other hand, the aromatogram to be carried out by the method of Vincent, which consists of depositing the disks of filter paper impregnated with the extract. After incubation at $37^{\circ} \mathrm{C}$ for 48 hours, zones of inhibition appear around these sterile disks.

2) Determination of the Minimum Inhibitory Concentration (MIC) and Minimum Bactericidal Concentration (MBC)

The minimum inhibitory concentration is the lowest concentration of extracts that inhibits the bacteria tested. It performed on liquid environment. Essential Oil Dilution series ranging from 20 to $0.15 \mu \mathrm{l} / \mathrm{ml}$ were prepared in test tubes containing Luria-Bertani broth with $0.15 \%$ of the agar. Each tube was inoculated with a bacterial suspension adjusted to $10^{6} \mathrm{CFU} / \mathrm{ml}$. Controls containing environments with bacteria, i.e., only the essential oil was included. The tubes were, then, incubated at $37^{\circ} \mathrm{C}$ for 24 hours. MIC values were defined as the lowest essential oil concentrations at which no growth was recorded.

Minimum Bactericidal Concentration (MBC) is the lowest concentration of extract that is able to kill more than $99.9 \%$ of the initial bacterial inoculum (less than $0.01 \%$ of survivors) [10]. Each test performed in triple. The same concentration range, performed by the liquid macrodilution technique, used to determine the MIC and MBC of the extract to be tested. Samples were taken in the control tube and in each of the tubes without a bacterial pellet and then deposited "streaked" on MH agar. The inoculated dishes were incubated for 24 hours at $37^{\circ} \mathrm{C}$.

\section{3) Evaluation of the antioxidant power}

The antioxidant activity of the various extracts was evaluated for reduction of the radical DPPH (1,1-diphenyl-2-picryl-hydrazyl), according to the protocol described by Sanchez-Moreno [11]. For this reason, solutions with increasing concentrations are prepared by dilution of stock extract solution and ascorbic acid ( 0 to $0.15 \mathrm{mg} / \mathrm{ml}$ ) used as standard. The DPPH solution is prepared by solubilizing $6 \mathrm{mg}$ of DPPH in $200 \mathrm{ml}$ of ethanol. Method consists in mixing in a tube, $2 \mathrm{ml}$ of the freshly prepared DPPH solution with $100 \mathrm{ml}$ of the solution. A negative (or white) control is prepared in parallel with methanol. The whole then incubated in the dark for 30 minutes and the absorbance measured at 517 $\mathrm{nm}$. Three optical density measurements were determined. 
The evaluation of the antioxidant activity expressed as a percentage inhibition of the radical DPPH according to the following rule [12].

$$
\% \mathrm{PI}=\frac{(A b s \text { control }-A b \text { sample })}{A b s \text { control }} \times 100
$$

When, "\% PI" is the inhibition percentage and "Abs" is the absorbance.

This formula makes it possible to draw the straight line which represents the variation of the percentage of inhibition as a function of the different concentrations of each sample $(y=a x+b)$. From this, it is possible to deduce the concentration that can reduce by $50 \%$ of DPPH for the sample studied and for ascorbic acid. This concentration generally called IC50, calculated according to the following equation:

$$
\mathrm{IC} 50=\frac{50-b}{a}
$$

where "IC50" is the concentration needed to reduce by $50 \%$ on DPPH, "a" is the slope of the line and " $\mathrm{b}$ " is the interception of the straight line, and the IC50 value determined graphically by linear regression.

Moreover, the results were plotted in percentage trapping activity versus sample concentration. Inhibition concentration (IC50) defined as the amount of crude methanol extract required for $50 \%$ of the free radical scavenging activity. The IC50 value calculated from the plots, as the antioxidant concentration required providing $50 \%$ free radical scavenging activity.

\section{Results and Discussions}

\subsection{Antibacterial Activity}

The antibacterial activities of methanolic extract of Salvadora persica against the three pathogenic organisms listed in Table 1. It observed that the three strains react differently to antibiotics, which shows that those strains are resistant to $\mathrm{K}$, CTX, C and TIM, on the other hand, sensitive to FOS and CT.

The extract of Salvadora persica was active with the three strains tested, the diameter of the zone of the least inhibition observed in Enterobacter cloacae. The results of the disk diffusion test showed higher antibacterial activity against the bacteria. Salvadora persica extract found to have better antibacterial activity than antibiotics to study, and these results are consistent with the results of other studies [14] [15].

Table 1. Diameters of antibiotic inhibition zones and Salvadora Persica extract (in mm).

\begin{tabular}{ccccccccc}
\hline & \multicolumn{4}{c}{ ANTIBIOTIC } & \multicolumn{3}{c}{ Extract of SP (mm) } \\
\hline STRAINS & $\mathrm{K}$ & CTX & FOS & CT & C & TIM & SP \\
Enterobacter cloacae & $\mathrm{R}$ & $\mathrm{R}$ & $\mathrm{S}$ & $\mathrm{S}$ & $\mathrm{R}$ & $\mathrm{R}$ & 14 \\
Acinetobacter baumanni & $\mathrm{R}$ & $\mathrm{R}$ & $\mathrm{S}$ & $\mathrm{S}$ & $\mathrm{R}$ & $\mathrm{R}$ & 18 \\
Pseudomonas aeruginosa & $\mathrm{R}$ & $\mathrm{R}$ & - & $\mathrm{S}$ & $\mathrm{R}$ & $\mathrm{R}$ & 20 \\
\hline
\end{tabular}

K: Kanamycin; CTX: Cefotaxim; FOS: Fosfomycin; CT: Colistine; C: Chloramphenicol; TIM: Ticarcilin. Results are scored according to standards (R: resistant strain, S: sensitive strain) [13]. 
Additionally, Sofrata et al. identified a volatile compound: benzyl isothiocyanate in extracts of Salvadora persica. In their studies, benzyl isothiocyanate showed a fast and powerful bactericidal effect against the bacteria, the authors speculated that benzyl isothiocyanate could penetrate through the outer bacterial membrane and possibly interfere with bacterial redox systems; thus, hinder the bacterium's ability to maintain its membrane potential [16].

\subsection{Minimal Inhibitory Concentration and Minimal Bactericidal Concentration}

The dilution method consists in determining the lowest concentration of an antimicrobial agent necessary to inhibit the growth of a microorganism [17]. The effectiveness of the tested extract evaluated by measuring two concentrations: the MIC and the MBC. These concentrations allow us to know the nature of the antimicrobial activity of the extract: bacteriostatic or bactericidal. Table 2 shows the MIC and MBC extracts of Salvadora persica extract on Pseudomonas aeruginosa, Acinetobacter baumanni and Enterobacter cloacae.

Concerning MIC and MBC Enterobacter cloacae and Acinetobacter baumani, they are less sensitive than Pseudomonas aeruginosa. Meanwhile, the latter is the most sensitive $(\mathrm{MIC}=0.02)$. It observed that these results reported high values; these emerging pathogens, are becoming a significant health problem because of their remarkable ability to flood and multi-class antimicrobial resistance and survive in nosocomial environments [18] [19].

\subsection{Chemical Analyzes}

\section{1) The Output:}

The extract obtained from Salvadora persica is brownish in color with a very strong and persistent odor. From $80 \mathrm{~g}$ of Miswak powder, we obtained about $19 \%$ of organic matter extractable by methanol.

\section{2) Antioxidant activity}

The antioxydant activity of Salvadora Persica methanolic extract and the standard antioxidant (ascorbic acide), versus the DPPH radical, were evaluated using a spectrometer following the reduction of that radical along with the change from the color purple (DPPH) to the yellow one measurable at $517 \mathrm{~nm}$. This reduction capacity is determined by a decrease in the absorbance induced by antiradical substances [20].

The value obtained allowed us to trace the test curves (absorbance versus concentrations) for ascorbic acid and Salvadora persica extract. These curves, showing an exponential pace, represented by two linear parts: a descending line representing the reduction of the radical DPPH and the horizontal which indicates that the reduction of the DPPH is total.

Figure 1 shows the DPPH reduction curve as a function of the concentration of ascorbic acid. Table 3 represents the IC50 value of Salvadora persica extract. These results show that ascorbic acid has a very strong anti-radical activity with IC50 [12] equal to $0.097 \mathrm{mg} / \mathrm{ml}$, this value is close to that obtained by Bentabet 


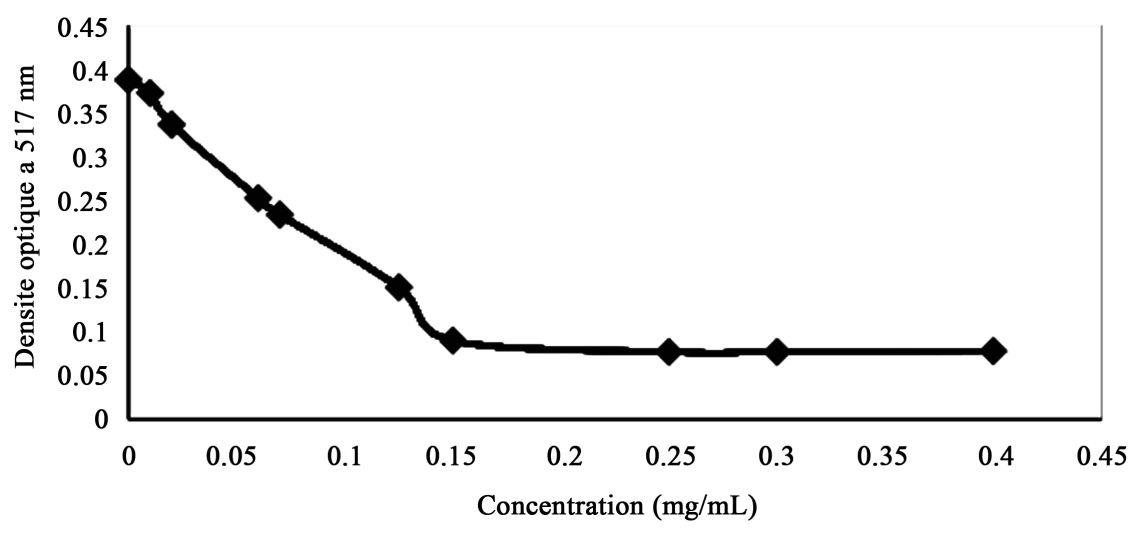

Figure 1. Reduction curve of DPPH as a function of the concentration of ascorbic acid.

Table 2. MIC and MBC of the methanolic extract against microorganisms.

\begin{tabular}{ccc}
\hline Strains & MIC $(\mathrm{mg} / \mathrm{ml})$ & $\mathrm{MBC}(\mathrm{mg} / \mathrm{ml})$ \\
\hline Enterobacter cloacae & 0.08 & 0.08 \\
Acinetobacter baumanni & 0.04 & 0.04 \\
Pseudomonas aeruginosa & 0.02 & 0.02 \\
\hline
\end{tabular}

Table 3. IC50 value of Salvadora persica extracts.

\begin{tabular}{cc}
\hline Extracts & IC50 (mg/mL) \\
\hline Ascorbic acid & 0.097 \\
Methanolic extract & 15.469 \\
\hline
\end{tabular}

[21]. Which is of the order of $0.08 \mathrm{mg} / \mathrm{ml}$. Comparing with ascorbic acid, the essential oil has the lowest antioxidant power.

According to the results found, the methanolic extract has a moderate antioxidant capacity. Their IC50 is $15.47 \mathrm{mg} / \mathrm{ml}$ which is much higher than that of ascorbic acid whose value is of the order of $0.097 \mathrm{mg} / \mathrm{ml}$. $\mathrm{ml}$ (Figure 1).

\section{Conclusion}

Salvadora persica proved to be a useful natural source with high effective results in cleaning the oral cavity. It protects from tooth decay and prevents every periodontal disease. Besides, it has several other biological effects. This study, therefore, illustrates the moderate and the strongest antibacterial activities of the Miswak's methanol extracts against the tested pathogens. Consequently, further studies needed in vivo and in vitro on a large number of clinical isolates of the three bacteria, mentioned in this piece of work, to continue researches in this field, also to standardize the inhibitory effects of the Miswak extracts against those emergent pathogens.

\section{References}

[1] Schauenberg, P. (2006) Guides des plantes médicinales analyse, description et utili- 
sation de 400 plantes. Edition delachaux et niestlé, Paris, 33-34.

[2] Siddiqui, Y.M., Ettayebi, M., Haddad, A.M. and Al-Ahdal, M.N (1996) Effect of Essential Oils on the Enveloped Viruses: Antiviral Activity of Oregano and Clove Oils on Herpes Simplex Virus Type 1 and Nawcastle Disease Virus. Medical Science Research, 24, 185-186.

[3] Upadhyay, R.K., Ahmad, S., Tripathi, R., Rohtagi, L. and Jain, S.C. (2010) Screening of Antimicrobial Potential of Extracts and Pure Compounds Isolated from Capparis decidua. Journal of Medicinal Plants Research, 4, 439-445.

[4] Budhiraja, S.S., Cullum, M.E., Evangelistra, L. and Habanova, S.T. (1999) Biolgical Activity of Melaleuca alternifolia (Tea Tree) Oil Component, terpinen-4-ol, in $\mathrm{Hu}$ man Myelocytic Cell Line HL-60. Journal of Manipulative and Physiological Therapeutics, 22, 447-453. https://doi.org/10.1016/S0161-4754(99)70033-3

[5] Peana, A.T., Moretti, M.D. and Juliano, C. (1999) Chemical Composition and Antimicrobial Action of the Essential Oil of Salvia desoleana and S. sclarea. Planta Medica, 65, 752-745. https://doi.org/10.1055/s-2006-960857

[6] Carson, C.F. and Riley, T.V. (1995) Antimicrobial Activity of the Major Components of the Essential Oil of Melaleuca alternifolia. The Journal of Applied Bacteriology, 78, 264-269. https://doi.org/10.1111/j.1365-2672.1995.tb05025.x

[7] Goyal, M., Sasmal, D. and Nagori, B.P. (2011) Salvadora persica (Meswak): Chewing Stick for Complete Oral Care. International Journal of Pharmacology, 7, 440-445. https://doi.org/10.3923/ijp.2011.440.445

[8] Sofrata, A.H., Claesson, R.L.K., Lingström, P.K. and Gustafsson, A.K. (2008) Strong Antibacterial Effect of Miswak against Oral Microorganisms Associated with Periodontitis and Caries. Journal of Periodontology, 79, 1474-1479. https://doi.org/10.1902/jop.2008.070506

[9] Mammad, Z., Djassinra, T., Kribii, A. and Ounine, K. (2015) Evaluation de l'activité antibactérienne du Salvadora Persicaet leur caractérisation chimique. International Journal of Innovation and Scientific Research, 18, 407-416.

[10] Smith-Palmer, A., Stewart, J. and Fyfe, L. (1998) Antimicrobial Properties of Plant Essential Oils and Essences against Five Important Food-Borne Pathogens. Letters in Applied Microbiology, 26, 118-122.

https://doi.org/10.1046/j.1472-765X.1998.00303.x

[11] Sanchez-Moreno, C. (2002) Review: Methods Used to Evaluate the Free Radical Scavenging Activity in Food and Biological Systems. International Journal Of Food Science and Technology, 3, 121-137. https://doi.org/10.1177/1082013202008003770

[12] Djeridane, A., Yousfi, M., Nadjemi, B., Maamri, S., Djireb, F. and Stocker, P. (2006) Phenolic Extracts from Various Algerien Plants as Strong Inhibitors of Porcine Liver Carboxyl Esterase. Journal of Enzyme Inhibition and Medicinal Chemistry, 21, 719-726. https://doi.org/10.1080/14756360600810399

[13] Robin, F., Aggoune-khinache, N., Delmas, J., Nim, M. and Bonnet, R. (2010) Novel V/M Metallo-\{beta\}-Lactamase Variant from Clinical Isolates of Enterobacteriaceae from Algeria. Antimicrobial Agents Chemotherapy, 54, 466-470.

https://doi.org/10.1128/AAC.00017-09

[14] Al-Sieni, A.I. (2014) The Antibacterial Activity of Traditionally Used Salvadora persica L (Miswak) and Commiphora gileadensis (Palsam) in Saudi Arabia. African Journal of Traditional, Alternative and Complementary Medicines, 11, 23-27.

[15] Mohammed, S.G. (2013) Comparative Study of in Vitro Antibacterial Activity of Miswak Extracts and Different Toothpastes. American Journal of Agricultural and 
Biological Science, 8, 82-88. https://doi.org/10.3844/ajabssp.2013.82.88

[16] Sofrata, A., Santangelo, E.M., Azeem, M., Borg-Karlson, A.-K., Gustafsson, A. and Benzyl, P.K. (2011) Isothiocyanate, a Major Component from the Roots of Salvadora persica Is Highly Active against Gram-Negative Bacteria. PLoS ONE, 6, e23045.

[17] Derwich, E., Benziane, Z. and Boukir, A. (2010) GC/MS Analysis and Antibacterial Activity of the Essential Oil of Mentha pulegium Grown in Morocco. Research Journal of Agriculture and Biological Sciences, 6, 191-198.

[18] Magiorakos, A.-P., Srinivasan, A. and Carey, R.B. (2012) Multidrug-Resistant, Extensively Drug-Resistant and Pandrug-Resistant Bacteria: An International Expert Proposal for Interim Standard Definitions for Acquired Resistance. Clinical Microbiology and Infection, 18, 268-281.

https://doi.org/10.1111/j.1469-0691.2011.03570.x

[19] Elabd, F.M., Al-Ayed, M.S.Z., Asaad, A.M., Alsareii, S.A., Qureshi, M.A. and Musa, H.A.-A. (2015) Molecular Characterization of Oxacillinases among Carbapenem-Resistant Acinetobacter baumannii Nosocomial Isolates in a Saudi Hospital. Journal of Infection and Public Health, 8, 242-247. https://doi.org/10.1016/j.jiph.2014.10.002

[20] Majhenic, L., kerget, M.S. and Knez, Z. (2007) Antioxidant and Antimicrobial Activity of Guarana Seed Extracts. Food Chemist, 104, 1258-1268.

https://doi.org/10.1016/j.foodchem.2007.01.074

[21] Bentabet, N., Boucherit-Otmani, Z. and Boucherit, K. (2014) Composition chimique et activité antioxydante d'extraits organiques des racines de Fredolia aretioides de la région de Béchar en Algérie. Journal Phrmacognosie, 12, 364-371. 